\title{
Biomedical Applications of Interpenetrating Polymer Network System
}

\author{
Mohd Fuzail Qadri ${ }^{*}$ Rishabha Malviya and Pramod Kumar Sharma
}

Department of Pharmacy, School of Medical and Allied Sciences, Galgotias University, Greater Noida, Gautam Buddha Nagar, Uttar Pradesh, India

\begin{abstract}
Interpenetrating polymer network (IPN) has been regarded as one of the novel technology in recent years showing the superior performances over the conventional techniques. This system is designed for the delivery of drugs at a predetermined rate and thus helps in controlled drug delivery. Due to its enhanced biological and physical characteristics like biodegradability, biocompatibility, solubility, specificity and stability, IPN has emerged out to be one of the excellent technologies in pharmaceutical industries. This article focuses mainly on the biomedical applications of IPN along with its future applicability in pharmaceutical research. It summarizes various aspects of IPN, biomedical applications and also includes the different dosage forms based on IPN.
\end{abstract}

Keywords: Biomedical, double network, drug delivery, IPN, tissue engineering.

\section{INTRODUCTION}

The concept of IPN goes back as far as 1914 and the first interpenetrating polymer network (IPN) was invented by Aylsworth and the term IPN was firstly given by Miller in 1960s in a scientific study about polystyrene network [1]. An Interpenetrating polymer network may be defined as any material which contains two or more polymers in the network form [2]. IPN is obtained when at least one of the polymers is synthesized or cross-linked in the immediate presence of the other polymer without any covalent bond between them [3].

In other words, IPN may also be defined as the combination of two or more polymers in the network form in which one polymer is cross-linked in the presence of other [4]. There are three conditions of polymer which are necessary in the composition of IPN. These conditions are as follows [5]:-

1) At least two polymers must be synthesized and crosslinked in the presence of the other.

2) Both polymers have similar kinetics.

3) Polymers are not dramatically phase separated.

An IPN is differentiating from other polymer combination in two ways [6]:-

1) IPN swells, but does not dissolve in the solvent.

2) Prevents the action of creep and flow.

They are also different from polymer complex and graft co-polymer because they either involve in chemical bond or in low degree of cross-linking. From this point of view only, IPN can be generally named as "polymer alloys" [7]. IPN is not

*Address correspondence to this author at the Department of Pharmacy, School of Medical and Allied Sciences, Galgotias University, Plot No. 2, Sector 17-A, Yamuna Expressway,Greater Noida, Gautam Buddha Nagar, Uttar Pradesh, India; Tel: +91 9716037762; E-mail: qadri14@gmail.com prepared by normally mixing the two or more polymers and also does not produce from co-polymers. IPN based drug delivery system may follow zero order pattern with less fluctuation [8]. IPN is regarded as novel biomaterial. A combination of polymers, i.e. synthetic and natural polymers, is useful in increasing the release of short half-lived drug under physiological condition [9]. If we increase the mechanical properties of IPN, it will be acceptable for preparing microsphere for controlled drug delivery [10]. The chemical and physical combination method as well as properties of multipolymers play as important role in the controlled release of the drug because they help to provide a convenient route for the modification of properties to meet specific needs. Among these methods, IPN based drug delivery system is one of the newly developed method for designing the novel controlled release drug delivery system [11].

Double network gels also obtained from interpenetrating polymer network where the properties of two networks can be done in contrast such as, rigidity, molecular weight, network density etc. They are generally synthesized with the help of two steps:- in first step, they are synthesized by sequential free-radical polymerization process. In this process, the highly relative molecular mass is neutral. In the second step, polymer network is incorporated with in a swollen heterogeneous polyelectrolyte $1^{\text {st }}$ network [12].

IPN formulation is one of the important/successful methods for developing a product with better physico-mechanical properties than the normal polyblends [13]. IPN can be made in different ways. IPN is also found in the form of latex which is known as interpenetrating electrometric network (IEN) [14]. Gradient IPN is one of the other forms which is formed when the film made with a network of one polymer on the one surface and the network of another polymer on the other surface, there is a gradient inside the film. On the other hand, when one polymer is cross linked and another is linear or branched, it is called semi-IPN [15]. 
IPNs can be prepared through different techniques as given in the literature but in-situ technique proves that it is the most convenient technique. In this technique, all reactants are combined together and reaction can take place with the formation of two networks which can be started at the same time [16]. The procedure for the synthesis of IPNs can be divided in to two categories-

1. Simultaneous synthetic method: In simultaneous synthetic method, both monomers are mixed together to form polymer network simultaneously through different reaction routes.

2. Sequential synthetic method: In sequential synthetic method, different network reactions are controlled sequentially by adding different monomers. Now a days, mostly commercial materials are prepared by sequential IPNs, because of their flexibility and easy to process ability.

When IPNs are used for coating purpose, they cannot be prepared by the sequential or simultaneous interpenetrating polymerization because of the presence of volatile monomer. For this purpose, they can be prepared from preforming prepolymers which contain complementary functional groups that increase their miscibility [17]. In IPNs, cross linking of mutual chain entanglement produce finer dispersion of one polymer in to the other [18].

Advantages of IPN [19, 20]: There are the following inherent advantages due to which IPN system gained huge popularity in the modern era of polymers. They are as follows-

1. IPN system helps in increasing the mechanical strength, phase stability and biological acceptability of the final product.

2. IPN is also helpful in producing the synergistic effect from the component polymer.

3. Due to the infinite zero-viscosity of the gel, phase separation between the component polymers is not possible.

4. Due to permanent interlocking of the network segment, thermodynamic incompatibility can be made to overcome as the reacting ingredients are blended thoroughly at the time of synthesis.

5. IPN also potent to develop the controlled release system for delivering the drug.

6. When the blends are subjected to stress they keep the phases separate.

Disadvantages of IPN [21, 22]: The main disadvantage of IPN is that, sometimes the polymers interpenetrate to such an extent and the drug released from the matrix becomes difficult. The problem with the non-covalent system is that it can also be a problem with the covalent system due to the lack of an effective interface.

Features of IPN [2, 23]: There are the following ideal characteristics of IPN which are as follows-

1. In ideal IPN creep and flow is suppressed.

2. IPN can swell but does not dissolve in solvent.

3. IPN has high tensile strength.
4. Most ideal IPNs are heterogeneous systems which contain one rubbery phase and one glassy phase to produce a synergistic effect yielding.

5. When the blends are subjected to stress, they keep the phases separated together.

6. IPN mainly forms insoluble network.

7. IPN systems differ mainly due to the number and types of cross-links.

8. They show adhesive property.

9. Hence, IPN based systems have gained good potential to develop the controlled release delivery of drugs.

IPN based Drug Delivery System: IPN based drug delivery systems are used to deliver the drug at a specific rate for desired period of time with low fluctuation.

Now a days, there are many approaches which are being used for improving the delivery of therapeutic materials likefilms, hydrogels, tablets, capsules, microspheres, sheets, sponges, matrix, transdermal patches, nanoparticles etc. some of the important IPN based drug delivery systems are discussed here [24].

Films: IPN based films are used as piezodialysis membrane which are non-mosaic membrane. The important application of IPN delivery system is the uralkyd/poly (glycidylmethacrylate) based film which shows better mechanical and tensile strength $[3,25]$. Biodegradable collagen films or matrices have served as scaffolds for the survival of transfected fibroblasts [26].

IPN based films which are prepared by the mixture of collagen and polyvinyl alcohol, cross-linked with glutaraldehyde vapor shows depot formulation for recombinant human growth hormones [27]. In many animal models, after implantation of transfected cells, a long term expression of the foreign gene has not been achieved [28]. Suh et al., studied the graft copolymerization of type I atelocollagen onto the surface of polyurethane (PU) films treated with ozone was performed [29]. It has been observed that they could enhance an attachment and proliferation of fibroblasts and growth of cells.

An interesting use of thermo-responsive polymer films was shown by Zakharchenko et al., prepared a belayed of PVCL on top of PNIPAAm with encapsulated magnetic nanoparticles [30]. At temperatures greater than the lower critical solution temperature (LCST) the films were flat and allowed for adsorption of nanoparticles, cells or drugs onto the surface, upon cooling the films rolled up entrapping the absorbed particles which could then be released by heating again. This is a novel approach for the encapsulation and release of nanoparticles and cells with the addition of the magnetic particles allowing manipulation of the films by an external field [31]. Some of the IPN based films with their applications are shown in Table $\mathbf{1}$.

Hydrogel: To determine potential in a drug delivery system, hydrogel formulations were prepared by the combination of polymers [45]. Hydrogels are the three dimensional polymeric network which are chemically cross-linked [46] and have the capacity to hold the water in its structure due to the presence of hydrophilic functional groups [47]. 
Table 1. List of the drugs delivered through IPN based films.

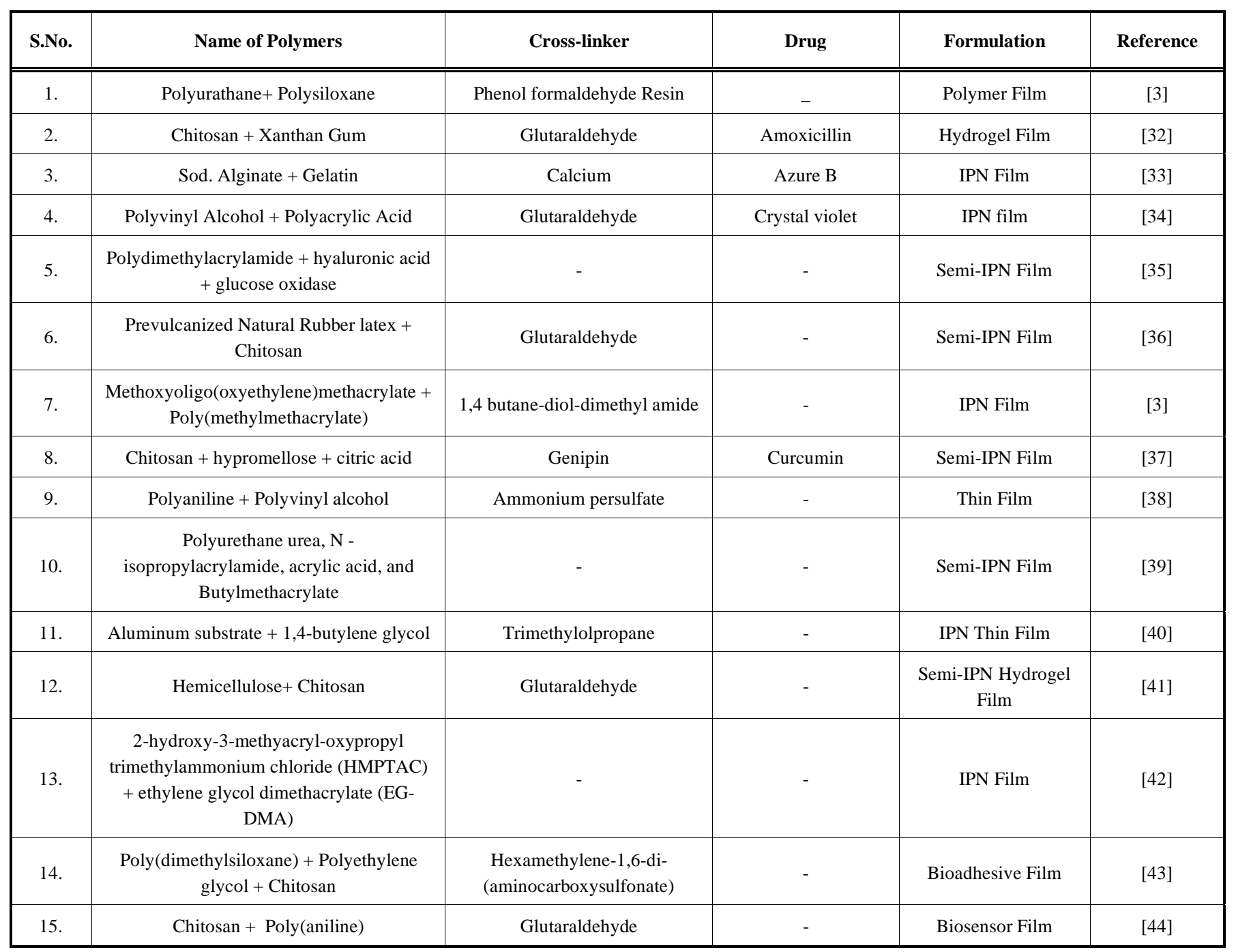

Development of Smart Drug Delivery System (SDDS) which is also known as Stimuli-sensitive delivery system is one of the major success in drug delivery by IPN Hydrogels. The concept of SDDS is based on the conversion of physicchemical properties of the polymer system [48]. Hydrogels are widely used in drug carrier because of its self-application and due to its easily manufacturing. IPN Hydrogels were prepared to increase the mechanical strength of the natural polymers. Hydrogels was also found resilient and stable [49]. Environmentally sensitive hydrogels can be produced from hydrophilic, stimuli-responsive polymer networks that can change the volume in response to an external signal such as a change in temperature or chemical environment. These materials are attractive and candidate for various biomedical applications and artificial muscles [50]. In situ forming IPN hydrogels of calcium alginate and dextran hydroxyethylmethacrylate were developed and evaluated for protein release as well as for the behavior of embedded cells. It was observed that after an initial burst release bovine serum albumin was gradually released from the IPN hydrogels for up to 15 days. Encapsulation of expanded chondrocytes in the IPNs revealed that cells remained viable and were able to redifferentiate. IPN was described as a promising system as injectable in situ forming hydrogels for protein delivery and tissue engineering applications [51].

Eltjani-Eltahir Hago et al. developed interpenetrating polymer network PVA/GE hydrogels by a combination of enzymatic and physical methods, used freezing-thawing process and in situ with synthesis of gelatin/mTG in PVA solution. The morphology and crystalline structures of interpenetrating polymer network PVA/GE were also observed by some experimental analysis techniques, such as scanning electronic microscope (SEM). Moreover, in order to understand the initial behavior of fibroblasts cells, proliferation was assessed in vitro using fibroblast like L 929 cell culture [52].

Steffensen et al., developed soft hydrogels interpenetrating silicone, a polymer network for drug-releasing medical devices. IPN materials with PHEMA content in the range of $13 \%-38 \%(\mathrm{w} / \mathrm{w})$ were synthesized by using carbon dioxidebased solvent mixtures under high pressure. These IPNs were characterized with regard to microstructure as well as ability of the hydrogel to form a surface-connected hydrophilic carrier network inside the silicone. A critical limit for hydrogel connectivity was found both via simulation and by 
Table 2. List of the drugs delivered through IPN based hydrogel.

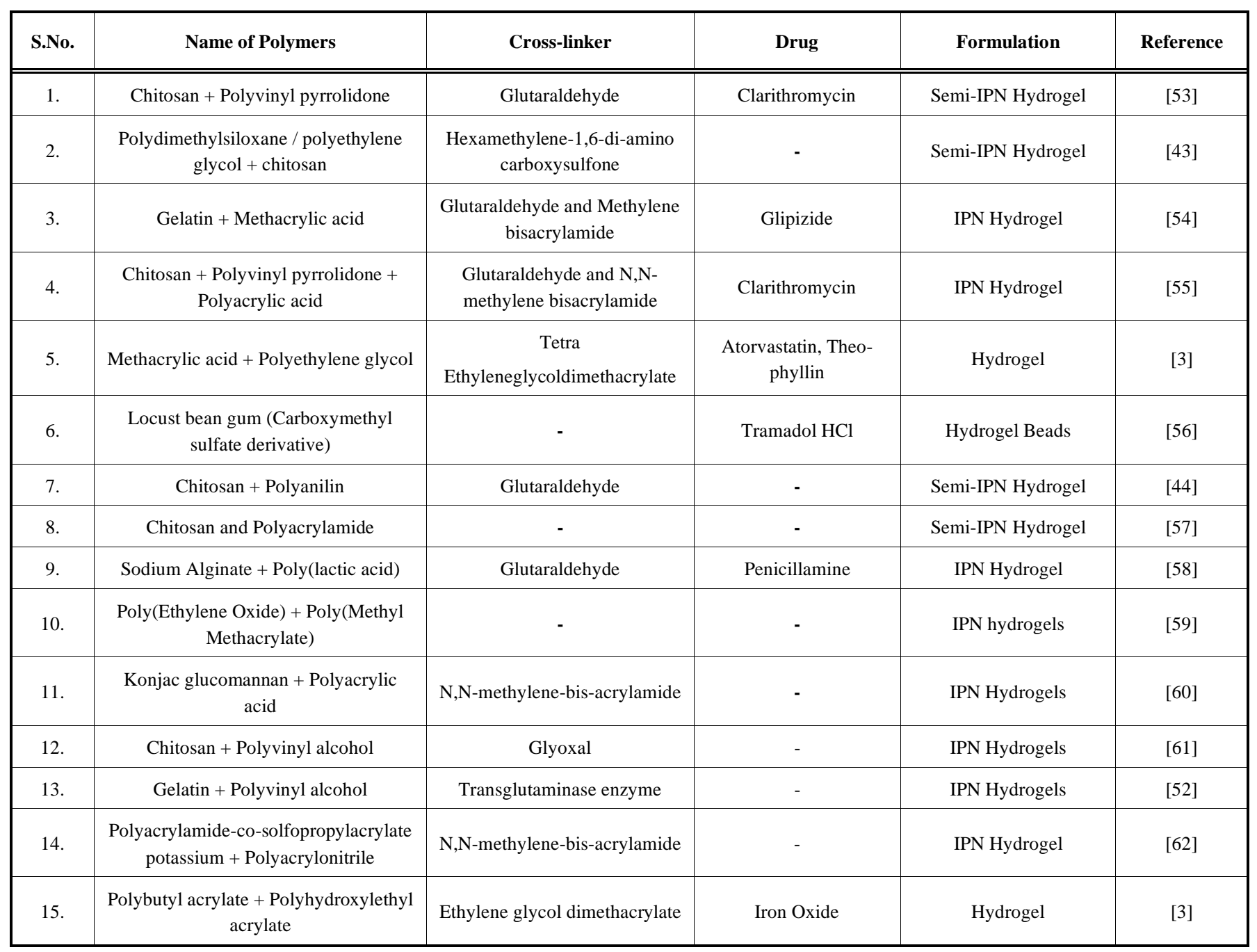

visualization of water uptake in approximately $25 \%(\mathrm{w} / \mathrm{w})$ PHEMA, indicating that entrapment of gel occurs at low gel concentrations. The optimized IPN material was loaded with the antibiotic ciprofloxacin, and the resulting drug release was shown to inhibit bacterial growth when placed on agar, thus demonstrating the potential of this IPN material for future applications in drug-releasing medical devices [114]. Some of the IPN based hydrogels with their applications are shown in Table 2.

Microspheres: Microspheres are one of the classes of newest IPN based drug delivery system. Microspheres are free flowing powder, which are solid usually small spherical particles made up of natural or synthetic polymers and ideally having a particles size range from 1-1000 $\mu \mathrm{m}$ in diameter [63]. Microspheres are the carrier linked delivery system having a core which contains drug and outer layer of polymer as coating material [64]. IPN microspheres are the versatile carrier for controlled release of the drug and also for the targeting application because they encapsulate a wide range of drugs, increased bioavailability, biocompatibility, patient compliance and sustained release characteristics [65]. The hydrogel microspheres were developed from the formulation of polyvinyl alcohol and Guar gum for controlled delivery of Nifedipine by emulsion cross-linking method for livery of Nifedipine by emulsion cross-linking method for the treatment in severe hypertension [66].

Ray et al., developed an interpenetrating polymer network based on microspherical formulation from Sodium alginate and Polyvinyl alcohol by the emulsion cross-linking method in which Glutaraldehyde is used as a cross-linker. This IPN based formulation was used for the controlled release of Diclofenac Sodium [67]. Interpenetrating polymer network based microspheres was also used as a carrier for prolonged delivery of anti-cancer drug [3].

The rationale of developing mucoadhesive microspheres are that the formulation will be confined on the biological surface for localized delivery of the drug and the drug will be released close to the site of action with continuous enhancement of bioavailability [68]. IPN microspheres based on Xanthan gum and Polyvinyl alcohol were developed by emulsion cross-linked method to deliver the antiinflammatory drug. In this formulation Glutaraldehyde is used as cross-linker [8].

Al-Kahtani AA et al., prepared semi-interpenetrating polymer network microspheres of chitosan-(dextran-gacrylamide) by emulsion cross-linking method. 
Table 3. List of the drugs delivered through IPN based microspheres.

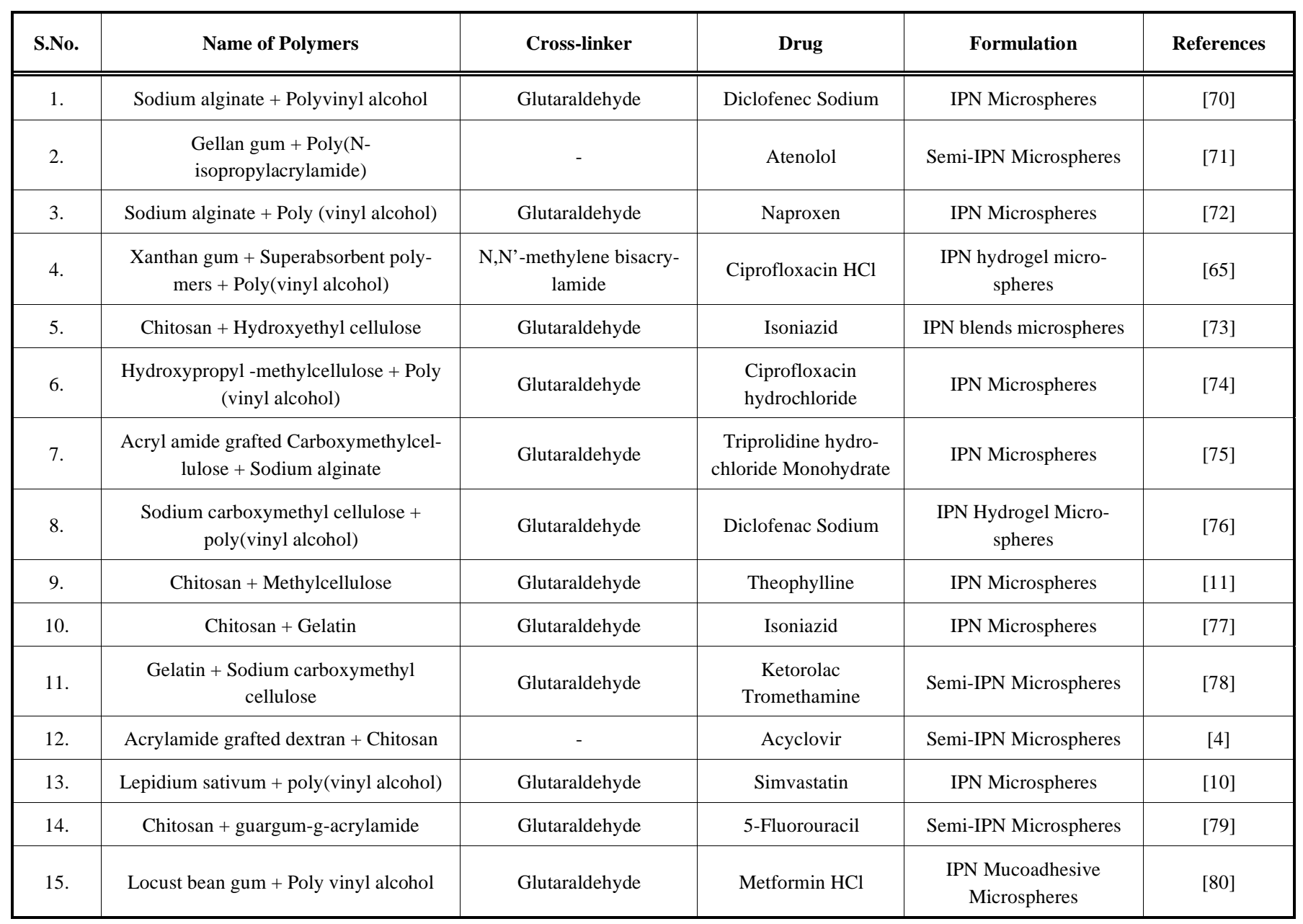

Glutaraldehyde was used as a cross-linking agent. Theophylline, an antiasthmatic drug was successfully incorporated into it by varying the ratio of dextran-g-acrylamide and amount of glutaraldehyde. The \% encapsulation efficiency in between 50 and 78 was achieved. In-vitro release studies of theophylline from these matrices at $\mathrm{pH} 1.2$ and 7.4 dissolution media demonstrated that slow release was extended up to $18 \mathrm{hrs}$ at $37^{\circ} \mathrm{C}$ [69]. Some of the IPN based microspheres with their applications are shown in Table $\mathbf{3}$.

Tablets: IPN can also be used for preparing an extended release matrix tablet from Chitosan / Carbapol inter-polymer complex. IPN based tablets are solid in nature and have great potential for anti-hypertensive action by blending with hydrophilic inter-polymer complexes or a hydrophobic waxy polymer [81]. Kulkarni et al., prepared IPN matrix tablets of sodium alginate and carrageenan for controlled release of Propranolol $\mathrm{HCl}$. by wet granulation/covalent cross-linking method and subsequently compressed into tablets. The pure drug showed rapid and complete dissolution within $60 \mathrm{~min}$ but IPN based tablets showed slower and prolonged drug release over $18 \mathrm{~h}$. The study concluded that the cross-linking time of granules affected the release of drug from IPN matrix [82]. Some of the IPN based tablets with their applications are shown in Table 4.
Sheet: Sheeting is one of the new method of producing IPN based drug delivery system [70]. These are mainly used in various types of wound dressings and scar management products [85]. An IPN composed of polymeric material like polyol (allyl carbonate) e.g. nouryset ${ }^{\circledR} 200$ and epoxy resin is developed by 70-95 parts by weight of polyol (allyl carbonate) by means of radical initiation and polymerizing partially or completely concurrently is an epoxy resin forming mixture composed of 10-90 weight \% of aliphatic or cycloaliphatic epoxide and 90-10 weight \% of polyol/anhydride adduct [86].

Sponges: IPN based sponges are also used as drug delivery system. They were mainly used in wound dressings and hemostyptics and also very helpful in the treatment of severe burns [87]. The advantages of collagen are-

a) Their capacity to easily take up large quantities of tissue exudates and provide smooth adherence to the wet wound bed with preservation of moist climate.

b) Its protection against mechanical harm and secondary bacterial infection.

Collagen also promotes growth and cellular mobility and hence, inflammatory cells can actively penetrate the porous scaffold. Due to this a highly vascularized granulation bed is formed which encourages the creation of new 
Table 4. List of the drugs delivered through IPN based tablets.

\begin{tabular}{|c|c|c|c|c|c|}
\hline S.No. & Name of Polymers & Cross-linker & Drug & Formulation & References \\
\hline 1. & Polyacrylamide grafted-sodium alginate + Sodium alginate & $\mathrm{Ca} 2+$ ion & Diltiazem $\mathrm{HCl}$ & $\begin{array}{l}\text { IPN Matrix } \\
\text { Tablets }\end{array}$ & [83] \\
\hline 2. & Sodium alginate + Carrageenan & - & Propranolol HCl & IPN matrix tablets & {$[82]$} \\
\hline 3. & Tamarind Seed Polysaccharide + Sodium Alginate & - & Propranolol $\mathrm{HCl}$ & $\begin{array}{l}\text { IPN hydrogel tab- } \\
\text { lets }\end{array}$ & [84] \\
\hline
\end{tabular}

Table 5. List of the drugs delivered through IPN based sponges.

\begin{tabular}{|c|c|c|c|c|c|}
\hline S.No. & Polymers & Cross-linkers & Drug & Formulation & References \\
\hline 1. & Chitosan + Poloxamer & - & - & Semi-IPN Sponges & {$[25]$} \\
\hline 2. & Elastin + Collagan & Glutaraldehyde & - & IPN Sponges & [89] \\
\hline 3. & Collagen + Fibronectin & Glutaraldehyde & Hyaluronic acid & IPN Sponges & {$[90]$} \\
\hline 4. & Elastin + Collagen & Glutaraldehyde & Glycosaminogycans & IPN Sponges & [91] \\
\hline 5. & Collagen + fibroblast & - & - & IPN Sponges & [92] \\
\hline
\end{tabular}

Table 6. List of the drugs delivered through IPN based capsules.

\begin{tabular}{|c|c|c|c|c|c|}
\hline S.No. & Name of Polymers & Cross-linker & Drug & Formulation & Reference \\
\hline \hline 1. & Polyacrylamide + polyvinyl alcohol & - & Crystal violet and Bromothymol blue & IPN Capsules & {$[94]$} \\
\hline
\end{tabular}

Table 7. List of biomedical applications.

\begin{tabular}{|c|c|c|c|c|}
\hline S.No. & Polymers & Drug & Applications & References \\
\hline 1. & Xanthan gum + Poly vinyl alcohol & Ciprofloxacin hydrochloride & Sustained release application. & {$[65]$} \\
\hline 2. & Polypropylene + Collagen gel & - & Abdominal wall repair in dogs & [95] \\
\hline 3. & Gum ghatti + poly vinyl alcohol & Ranitidine $\mathrm{HCl}$ & $\begin{array}{l}\text { Mucoadhesive microspheres for anti-ulcer drug } \\
\text { delivery }\end{array}$ & [96] \\
\hline 4. & $\begin{array}{l}\text { Polyacrylamide-co-ethylene glycol } \\
\text { +acrylic acid }\end{array}$ & - & $\begin{array}{l}\text { Modulate bone formation in the peri-implant } \\
\text { region in the rat femoral ablation model. }\end{array}$ & [97] \\
\hline 5. & $\begin{array}{c}\text { Chitosan }+ \text { Poly(acrylic acid-co- } \\
\text { acrylamide })\end{array}$ & Insulin & Superporous hydrogel for oral delivery & {$[98]$} \\
\hline 6. & Alginate + Chitosan & - & Improved cartilage tissue engineering & [99] \\
\hline 7. & Honeycomb + Collagen & - & Dermal tissue engineering & {$[100]$} \\
\hline 8. & Gelatin + Chitosan & Propranol $\mathrm{HCl}$ & Microsphere for nasal delivery. & {$[101]$} \\
\hline 9. & $\begin{array}{l}\text { Poly(2-acrylamide-2-metyl-propane sulfo- } \\
\text { nic acid) + Poly(N,N0-dimetylacrylamide) }\end{array}$ & - & Artificial cartilage & {$[12]$} \\
\hline 10. & Chitosan + Alanine & Chlorpheniramine & Oral controlled release of drug & {$[102]$} \\
\hline 11. & Collagen + hydrated gel & - & $\begin{array}{c}\text { Development of bioengineered } \\
\text { tissues such as heart valves, blood vessels and } \\
\text { ligaments }\end{array}$ & [103] \\
\hline
\end{tabular}


(Table 7) contd....

\begin{tabular}{|c|c|c|c|c|}
\hline 12. & Collagen + Chitosan & - & $\begin{array}{l}\text { Cartilage Scaffolds: Test anticancerous drugs and } \\
\text { in-vitro culture of human epidermoid carcinoma } \\
\text { cells (HEp-2) }\end{array}$ & [104] \\
\hline 13. & Locust Bean Gum + Poly (vinyl alcohol) & Metformin $\mathrm{HCl}$ & $\begin{array}{l}\text { Mucoadhesive Microspheres for } \\
\text { Controlled Release }\end{array}$ & [80] \\
\hline 15. & Chitosan + Guargum-g-acrylamide. & 5-Fluorouracil & $\begin{array}{l}\text { Microspheres for controlled release and improve } \\
\text { the bioavailability of drug }\end{array}$ & [79] \\
\hline 16. & Chitosan + Poloxamer & & Sponge for wound dressing & [105] \\
\hline 17. & Chitosan + Poly(vinyl pyrrolidone) & Clarithromycin & $\begin{array}{l}\text { H.pylori infection and management of peptic } \\
\text { ulcer }\end{array}$ & {$[55]$} \\
\hline 20. & $\begin{array}{l}\text { Hydroxyapatite }+ \text { Collagen }+ \text { bone } \\
\text { morphogenetic protein }\end{array}$ & - & $\begin{array}{c}\text { Acquired } \\
\text { and Congenital Orthopaedic defects }\end{array}$ & {$[106]$} \\
\hline 21. & Polyvinyl pyrrolidone + Chitosan & Amoxicilline & Controlled release system for antibiotics & [107] \\
\hline 22. & Collagen + Hydroxyapatite & - & Bone Tissue engineering & [108] \\
\hline 23. & $\begin{array}{l}\text { Polyacrylamide }+ \text { Poly(ethylene } \\
\text { glycol) }\end{array}$ & - & Controlled inflammatory response & [109] \\
\hline 24. & $\begin{array}{c}\text { Chitosan + Acryl amide-g-poly (vinyl } \\
\text { alcohol) }\end{array}$ & Cefadroxil & Micro gel for oral controlled release of drug & {$[110]$} \\
\hline
\end{tabular}

granulation tissue and epithelium on the wound [25]. Collagen-based materials can be produced into a threedimensional sponge for use as a wound dressing and as a support for cell cultured skin components [88]. Some of the IPN based sponges with their applications are shown in Table 5.

Capsules: IPN based capsules are one of the important approach for delivery of drug. IPN capsules are also used as drug delivery systems for sustain release of drug. Interpenetrating polymer networks (IPNs) hydrogel capsules consists of polyacrylamide and polyvinyl alcohol for sustained drug release. Supracolloidal IPN reinforced capsules using micron-sized colloidosomes of poly(methyl methacrylate-co-divinyl benzene) micro gels were used as scaffold via radical polymerization of the interior phase to produce hollow supracolloidal structures with a raspberry core-shell morphology [93]. Some of the IPN based capsules with their applications are shown in Table $\mathbf{6}$.

Biomedical Applications of IPN Based Drug Delivery System: Some of the biomedical applications of IPN based drug delivery systems with their applications are shown in Table 7.

\section{CONCLUSION}

It can be concluded from the whole literature survey that IPN based systems have wide applications in pharmaceuticals and medical sciences. IPN based polymeric materials can significantly change the release behavior of drug, protein/peptide, hormones and medicinal active agents. The study of IPN for drug delivery system may be helpful in understanding of critical diseases like acquired immune deficiency syndrome (AIDS), cancer and cardiac diseases as well as inflammatory diseases like rheumatoid arthritis, osteoarthritis and meningitis etc. IPN is mainly used as a carrier system for delivery of short biological half-life drugs. IPN has various advantages like excellent swelling capacity, specificity, and mechanical strength which play an important role in controlled and targeted drug delivery. Current study supports the theory that IPN can provide the resources to deliver the drugs at a prolonged controlled release for specific targets. IPN based biomaterials can serve as a potential candidate for tissue engineering and drug delivery system and are expected to become a useful matrix substance for various biomedical and therapeutic applications in the future. 


\section{CONFLICT OF INTEREST}

The authors confirm that this article content has no conflict of interest.

\section{ACKNOWLEDGEMENTS}

Authors would like to thanks Department of Pharmacy, School of Medical and Allied Sciences, Galgotias University and NISCAIR (National Institute of Science Communications and Information Resources), New Delhi for providing library facilities.

\section{REFERENCES}

[1] Lohani A, Singh G, Bhattacharya SS, Verma A. Interpenetrating polymer networks as innovative drug delivery systems. J Drug Deliver 2014; pp. 1-11

[2] Singh P, Kumar SKS, Keerthi TS, Mani TT, Getyala A. Interpenetrating polymer network (IPN) microparticles and advancement in novel drug delivery system: a review. Pharm Sci Monitor 2012; 3(1): 1826-37.

[3] Patel JM, Savani HD, Turakhiya JM, Akbari BV, Goyani M, Raj HA. Interpenetrating polymer network (IPN): A noval approach for controlled drug delivery. Uni J Pharm 2012; 01(01): 1-11.

[4] Rokhade AP, Patil SA, Aminabhavi TM. Synthesis and characterization of semi-interpenetrating microspheres of acrylamide grafted dextran and chitosan for controlled release of acyclovir. Carbohyd Polym 2007; 67: 605-13.

[5] Margaret MT, Brahmaiah B, Krishna PV, Revathi B, Nama S. Interpenetrating polymer network (IPN) microparticles an advancement in novel drug delivery system: a review. Int $\mathbf{J}$ Pharm Res Bio Sci 2013; 2(3): 215-24.

[6] Kudela V. "Hydrogels," in encyclopedia of polymer science and engineering. In: Kroschwitz JI. (Ed), New York NY, USA: Wiley, 1987; pp. 783-807.

[7] Work WJ, Horie K, Hess M, Stepto RFT. Definitions of terms related to polymer blends, composites, and multiphase polymeric materials. Pure Appl Chem 2004; 76(11): 1985-2007.

[8] Jain N, Sharma PK, Banik A, Gupta A, Bhardwaj V. Pharmaceutical and biomedical applications of interpenetrating polymer network. Curr Drug Therapy 2011; 6: 263-70.

[9] Banerjee S, Ray S, Maiti S, et al. Interpenetrating polymer network (IPN): A novel biomaterial. Int J Appl Pharm 2010; 2(1): 28-34.

[10] Jain N, Banik A, Gupta A. Novel interpenetrating polymer network microspheres of lepidium sativum and poly (vinyl alcohol) for the controlled release of simvastatin. Int J Pharm Pharm Sci 2013; 5(1): 125-30.

[11] Rokhade AP, Shelke NB, Patil SA, Aminabhavi TM. Novel interpenetrating polymer network microspheres of chitosan and methylcellulose for controlled release of theophylline. Carbohyd Polym 2007; 69(4): 678-87.

[12] Haque MdA, Kurokawa T, Gong JP. Super tough double network hydrogels and their application as biomaterials. Polymer 2012; 53: 1805-22.

[13] Dave VJ, Patel HS. Synthesis and characterization of interpenetrating polymer networks from trans-esterified castor oil based polyurethane and polystyrene. J Saudi Chem Soc 2013; doi: 10.1016/j.jscs.2013.08.001.

[14] Jaisankar SN, Muralisankar R, Seeni MK, Mandal AB. Thermoplastic interpenetrating polymer networks based on polyvinyl chloride and polyurethane ionomers for damping application. Soft Matt 2013; 11: 55-60

[15] Athawale VD, Kolekar SL, Raut SS. Recent developments in polyurethanes and poly(acrylates) interpenetrating polymer networks. J Macromolecul Sci Polymer Rev 2003; 43: 1-26.

[16] Vancaeyzeele C, Fichet O, Boileau S, Teyssie D. Polyisobutenepoly (methylmethacrylate) interpenetrating polymer networks: synthesis and characterization. Polymer 2005; 46: 6888-6896.

[17] Anzlovar A, Zigon M. Semi-interpenetrating polymer networks with varying mass ratios of functional urethane and methacrylate prepolymers. Acta Chimica Slovenica 2005; 52: 230-237.
[18] Merlin DL, Sivasankar B. Synthesis and characterization of semiinterpenetrating polymer networks using biocompatible polyurethane and acrylamide monomer. Eur Polymer J 2009; 45: 165-70.

[19] Wu X, He G, Gu S, Hu Z, Yao P. Novel interpenetrating polymer network sulfonated poly (phthalazinone ether sulfone ketone)/polyacrylic acid proton exchange membranes for fuel cell. J Membr Sci 2007; 295: 80-7.

[20] Sperling LH. Interpenetrating polymer network and related materials. New York: Plenum Press 1981; vol. 1: p. 265.

[21] Shidhaye S, Surve C, Dhone A, Budhkar T. Interpenetrating polymer network: An overview. Int J Res Rev Pharmacy Appl Sci; 2(4): 637-50.

[22] McNaught D, Wilkinson A. IUPAC compendium of chemical terminology (the "Gold Book"). Oxford: Blackwell Scientific Publications 2007; 2(2): 1815.

[23] Suresh PK, Suryawani SK, Dewangan D. Chitosan based interpenetrating polymer network (ipn) hydrogels: a potential multicomponent oral drug delivery vehicle. Pharmacie Globale. Int $\mathbf{J}$ Comp Pharm 2011; 8(1): 1-8.

[24] Hou X, Siow KS. Novel interpenetrating polymer network electrolytes. Elsev Polymer 2001; 42(9): 4181-8.

[25] Kim IY, Yoo MK, Seo JH, et al. Evaluation of semi-interpenetrating polymer networks composed of chitosan and poloxamer for wound dressing application. Int J Pharm 2007; 341: 35-43.

[26] Rosenthal FM, Kohler G. Collagen as matrix for neo-organ formation by gene-transfected fibroblasts. Anticancer Res 1993; 17: 1179-86.

[27] Cascone MC, Sim B, Downes S. Blends of synthetic and natural polymers as drug delivery systems for growth hormone. Biomaterials 1995; 16: 569-74.

[28] Ramaraj B, Radhakrishnan G. Hydrogel capsules for sustained drug release. J Appl Polymer Sci 1994; 51: 979-88.

[29] Park JC, Hwang YS, Lee JE. Type I Atelocollagen Grafting on to ozone-treated polyurethane films: cell attachment, proliferation and collagen synthesis. J Biomed Mater Res 2000; 52: 669-77.

[30] Ward MA, Georgiou TK. Thermoresponsive polymers for biomedical applications. Polymers 2011; 3: 1215-42.

[31] Zakharchenko S, Puretskiy N, Stoychev G, Stamm M, Ionov L. Temperature controlled encapsulation and release using partially biodegradable thermo-magneto-sensitive self-rolling tubes. Soft Matter 2010; 6: 2633-6.

[32] Thakur A, Monga S, Wanchoo RK. Sorption and drug release studies from semi-ipn of chitosan and xantham gum. Chem Biochem Engin Quarter 2014; 28(1): 105-15.

[33] Mohanan A, Vishalakhi B. Swelling and diffusion characteristics of ipn films compound of naalg and gelatin: transport of Azure B. Int J Polymer Mater Polymer Biomater 2009; 58(1): 561-80.

[34] Yue YM, Xu K, Liu XG, Chen Q, Sheng X, Wang PX. Preparation and characterization of interpenetration polymer network films based on poly(vinyl alcohol) and poly(acrylic acid) for drug delivery. J Appl Polymer Sci 2008; 108(6): 3836-42.

[35] Zhang K, Lian W, Liu S, Liu S. Multi-switchable bioelectrocatalysis based on semi-interpenetrating polymer network films prepared by enzyme-induced polymerization. J Electrochem Soc 2014; 161(9): 493-500.

[36] Lu G, Yu HP, Zeng ZQ, Luo YY. Preparation and properties of interpenetrating polymer network films from prevulcanized natural rubber latex/chitosan blends. Adv Mater Res 2011; 396-8: 400-6.

[37] Mayet N, Kumar P, Choonara YE, et al. Synthesis of a semiinterpenetrating polymer network as a bioactive curcumin film. AAPS Pharm Sci Tech 2014; 15(6): 1476-89.

[38] Honmute S, Ganachari SV, Bhat R, Kumar N, Huh DS, Venkataraman A. Studies on polyaniline-polyvinyl alcohol (pani-pva) interpenetrating polymer network (ipn) thin film. Int J Sci Res 2012; 1(02): 102-6

[39] Reddy TT, Takahara A. Simultaneous and sequential micro-porous semi-interpenetrating polymer network hydrogel films for drug delivery and wound dressing applications. Polymer 2009; 50(15): $3537-46$.

[40] Cui W, Tang D, Liu J, Yang F. Interfacial actions and adherence of an interpenetrating polymer network thin film on aluminum substrate. J Surface Engin Mater Adv Technol 2011; 1: 89-94.

[41] Karaaslan MA, Tshabalala MA, Buschle-Diller G. Semiinterpenetrating polymer network hydrogels based on aspen hemi- 
cellulose and chitosan: effect of crosslinking sequence on hydrogel properties. J Appl Polymer Sci 2012; 124: 1168-77.

[42] Sakai Y, Sadaoka Y, Matsuguchi M, Hirayama K. Water resistive humidity sensor composed of interpenetrating polymer networks of hydrophilic and hydrophilic methacrylate. Solid-State Sens Actuat 1991; 585(7): 562-5.

[43] Rodkate N, Wichai U, Boontha B, Rutnakornpituk M. Semiinterpenetrating polymer network hydrogels between polydimethylsiloxane/polyethylene glycol and chitosan. Carbohydr Polymer 2010; 81: 617-25.

[44] Kim SJ, Shin SR, Spinks GM, Kim IY, Kim SI. Synthesis and characteristics of a semi-interpenetrating polymer network based on chitosan/polyaniline under different ph conditions. J Appl Polymer Sci 2005; 96: 867-73.

[45] Bhardwaj V, Harit G, Kumar S. Interpenetrating polymer network (IPN): novel approach in drug delivery. Int $\mathbf{J}$ Drug Develop Res 2012; 4(3): 41-54

[46] Peppas NA, Bures P, Leobandung W, Ichikawa H. Hydrogels in pharmaceutical formulations. Eur J Pharm Biopharm 2000; 50(1): 27-46.

[47] Zhao Y, Kang J, Tan TW. Salt, $\mathrm{pH}$ and temperature responsive semi-interpenetrating polymer network hydrogel based on poly (aspartic acid) and poly (acrylic acid). Polymer 2006; 47(22): 770210 .

[48] Lohani A, Singh G, Bhattacharya SS, Verma A. Interpenetrating polymer networks as innovative drug delivery systems. J Drug Delivery $2014 ; 1-11$.

[49] Suri S, Christine ES. Photo-patterned collagen-hyaluronic acid interpenetrating polymer network hydrogels. Acta Biomaterial 2009; 5: 2385-97.

[50] Naficy S, Kawakami S, Sadeghovaad S, Wakisaka M, Spinks GM. Mechanical properties of interpenetrating polymer network hydrogels based on hybrid ionically and covalently crosslinked networks. J Appl Polymer Sci 2013; 130(4): 2504-13.

[51] Ray R, Maity S, Mandal S, Chatterjee TK, Sa B. Studies on the release of ibuprofen from al3+ ion cross-linked homopolymeric and interpenetrating network hydrogel beads of carboxymethyl xanthan and sodium alginate. Adv Polymer Technol 2011; 30(1): 1-11.

[52] Hago EE, Li X. Interpenetrating polymer network hydrogels based on gelatin and pva by biocompatible approaches: synthesis and characterization. Adv Mater Sci Engin 2013; 1-8.

[53] Vaghani SS, Patel MM. pH-sensitive hydrogels based on semiinterpenetrating network (Semi-IPN) of chitosan and polyvinyl pyrrolidone for clarithromycin release. Drug Develop Ind Pharmacy 2011; 37(10): 1160-9.

[54] Gupta NV, Satish CS, Shivakumar HG. Preparation and characterization of gelatin-poly(methacrylic acid) interpenetrating polymeric network hydrogels as a ph-sensitive delivery system for glipizide. Ind J Pharm Sci 2007; 69(01): 64-8.

[55] Gupta AK, Maurya SD, Dhakar RC, Singh RD. pH sensitive interpenetrating hydrogel for eradication of helicobacter pylori. Int $\mathbf{J}$ Pharm Sci Nanotechnol 2010; 3(2): 924-32.

[56] Maiti S, Chowdhary M, Chakraborty A, Ray S, Sa B. Sulfated locust bean gum hydrogel beads for immediates analgesics effects of tramadol hydrochloride. J Sci Ind Res 2014; 73: 21-8.

[57] Kim SJ, Shin SR, Kim NG, Kim SI. Swelling behavior of semi-interpenetrating polymer network hydrogels based on chitosan and poly(acryl amide). J Macromol Sci Part A: Pure Appl Chem 2005; 42(8): 1073-83.

[58] Prabhakar MN, Rao US, Babu PK, Subha MCS, Rao KC. Interpenetrating polymer network hydrogel membranes of PLA and SA for control release of penicillamine drug. Ind J Adv Chem Sci 2013; 1(4): 240-9.

[59] Kim SJ, Lee CK, Kim IY, Kim SI, Kim NG. Water sorption of interpenetrating polymer network hydrogels composed of poly (ethylene oxide) and poly (methyl methacrylate). High Perform Polymers 2004; 16(4): 515-23.

[60] Xue Y, Xuegang L, Benchao H. Preparation and characterization of interpenetrating polymer network hydrogels based on konjac glucomannan with various molecular weights and poly (acrylic acid) for controlled release. Chem Ind Eng Prog 2013; 31(1): 151-5.

[61] Gupta NV, Shivakumar HG. Interpenetrating network superporous hydrogels for gastroretentive application-preparation, swelling and mechanical properties. Turk J Pharm Sci 2012; 9(2): 127-38.

[62] Qiu Y, Park K. Superporous IPN hydrogels having enhanced mechanical properties. AAPS Pharm Sci Technol 2003; 4(4): 406-12.
[63] Lohani A, Gangwar PC. Mucoadhesion: a novel approach to increase gastroretention. Chronicl Young Sci 2013: 3: 121-8.

[64] Swapna S, Balaji A, Shankar MSU, Vijendar A. Microspheres as a promising mucoadhesive drug delivery system-review. Int J Pharm Sci Rev Res 2013; 23(2): 8-14.

[65] Bhattacharya SS, Mazahir F, Banerjee S, Verma A, Ghosh A. Preparation and in vitro evaluation of xanthan gum facilitated superabsorbent polymeric microspheres. Carbohydr Polymers 2013; 1: 64-72.

[66] Soppimath KS, Kulkarni AR, Aminabhavi TM. Controlled release of antihypertensive drug from the interpenetrating network poly(vinyl alcohol) guar gum hydrogel microspheres. J Biomater Sci Polymer 2000; 11: 27-43.

[67] Ray S, Maiti S, Banerjee S, et al. Interpenetrating polymer network (IPN): a novel biomaterial. Int J Appl Pharm 2010; 2(1): 28-34.

[68] Alexander A, Tripathi DKA, Verma T, Maurya J, Patel S. Mechanism responsible for mucoadhesion of mucoadhesive drug delivery system: a review. Int J Appl Biol Pharm Technol 2011; 2(1): 43445.

[69] Al-Kahtani AA, Sherigara BS. Controlled release of theophylline through semi-interpenetrating network microspheres of chitosan(dextran-g-acrylamide). J Mater Sci Mater Med 2009; 20: 1437-45.

[70] Banerjee S, Chaurasia G, Pal DK, Ghosh AK, Ghosh A, Kaity S. Investigation on cross-linking density for development of novel interpenetrating polymer network (IPN) based formulation. J Sci Ind Res 2010; 69: 777-84.

[71] Mundargi RC, Shelke NB, Babu VR, Patel P, Rangaswamy V, Aminabhavi TM. Novel thermo-responsive semi-interpenetrating network microspheres of gellan gum-poly ( $\mathrm{N}$-isopropylacrylamide) for controlled release of atenolol. J Appl Polymer Sci 2010; 116(3): 1832-41.

[72] Solak EK. Preparation and characterization of ipn microspheres for controlled delivery of naproxen. J Biomater Nano Biotechnol 2011; 2: 445-53.

[73] Angadi SC, Manjeshwar LS, Aminabhavi TM. Interpenetrating polymer network blend microspheres of chitosan and hydroxyl ethyl cellulose for controlled release of isoniazid. Int J Biological Macromol 2010; 47: 171-9.

[74] YerriSwamy B, Prasad CV, Reedy CLN, Mallikarjuna B, Rao KC Subha MCS. Interpenetrating polymer network microspheres of hydroxyl propyl methyl cellulose/poly (vinyl alcohol) for control release of ciprofloxacin hydrochloride. Cellulose 2011; 18: 349-57.

[75] Ramakrishna P, Rao KM, Sekharnath KV, et al. Synthesis and characterization of Interpenetrating polymer network microspheres of acryl amide grafted carboxy methylcellulose and sodium alginate for controlled release of triprolidine hydrochloride monohydrate. J Appl Pharm Sci 2013; 3(3): 101-8.

[76] Banerjee S, Siddiqui L, Bhattacharya SS, et al. Interpenetrating polymer network (IPN) hydrogel microspheres for oral controlled release application. Int J Biological Macromol 2012; 50(1): 198206.

[77] Angadi SC, Manjeshwar LS, Aminabhavi TM. Stearic acid-coated chitosan-based interpenetrating polymer network microspheres: controlled release characteristics. Ind Engin Chem Res 2011; 50(8): 4504-14.

[78] Kassem AA, Marzouk MA, El-Adawy SA, Dawaba AM. Formulation, in-vitro and in-vivo evaluation of semi-interpenetrating polymer network (Semi-IPN) microspheres of ketorolac tromethamine. J Life Med 2013; 1(3): 48-54.

[79] Sekhar EC, Rao KSV, Raju RR. Chitosan/guar-gum-g-acrylamide semi IPN microspheres for controlled release studies of 5Fluorouracil. J Appl Pharm Sci 2011; 01(08): 199-204.

[80] Bhardwaj V, Kumar S. Design and characterization of novel interpenetrating polymer network mucoadhesive microspheres of locust bean gum and pva for controlled release of metformin $\mathrm{HCl}$. Int Pharm Sci 2012; 2(2): 115-21

[81] Ghada AA, Mina IT. Design and in-vitro/in-vivo evaluation of novel nicorandil extended release matrix tablets based on hydrophilic-inter-polymer complexes and a hydrophobic waxy polymer. Eur J Pharm Biopharm 2008; 69: 1019-28.

[82] Kulkarni RV, Baraskar VV, Setty CM, Sa, B. Interpenetrating polymer network matrices of sodium alginate and carrageenan for controlled drug delivery application. Fiber Polymer 2011; 12: 3528 .

[83] Mandal S, Basu SK, Sa B. $\mathrm{Ca}^{2+}$ ion cross-linked interpenetrating network matrix tablets of polyacrylamide-grafted-sodium alginate 
and sodium alginate for sustained release of diltiazem hydrochloride. Carbohydr Polymer 2010; 82: 867-73.

[84] Kulkarnia RV, Baraskar VV, Alange VV, Naikawadi AA, Sa B. Controlled release of an antihypertensive drug through interpenetrating polymer network hydrogel tablets of tamarind seed polysaccharide and sodium alginate. J Macromol Sci 2013; 52(11): 163650.

[85] Schutyser JAJ, Boonstra TO. Interpenetrating polymer network of an aliphatic polyol(allyl carbonate) and epoxy resin. US Patent 1990; 4: 957-81,

[86] Dillon ME. Process for the manufacture of interpenetrating polymer network sheeting and useful articles thereof. US Patent 2006; 7: 87-135.

[87] Chvapil M. Considerations on manufacturing principles of a synthetic burn dressing: a review. J Biomed Mater Res 1982; 16: 24563.

[88] Doillon CJ. Porous collagen sponge wound dressings: in vivo and in vitro studies. J Biomater Applic 1987; 2: 562-78.

[89] Lefebvre F, Gorecki S, Bareilli R, Amedee J, Bordenave L, Rabaud M. New artificial connective matrix-like structure made of elastin solubilized peptides and collagens: elaboration, biochemical and structural properties. Biomaterials 1992; 13: 28-33.

[90] Doillon CJ, Silver FH. Collagen - based wound dressing effects of hyaluronic acid and fibronectin on wound healing. Biomaterials 1986; 7: 3-8

[91] Lefebvre F, Pilet P, Bonzon N, Daculsi G, Rabaud M. New preparation and microstructure of the Endo- Patch elastin-collagen containing glycosaminoglycans. Biomaterials 1996; 17: 1813-8.

[92] Prajapati RT, Chavally MB, Herbage D, Eastwood M, Brown RA. Mechanical loading regulates protease production by fibroblasts in three dimensional collagen substrates. Wound Repair Reg 2000; 8: 226-37.

[93] Stefan AF, Bon SC, Colver PJ. Colloidosomes as micron-sized polymerisation vessels to create supracolloidal interpenetrating polymer network reinforced capsules. Soft Mat 2007; 3: 194-9.

[94] Ramaraj B, Radhakrishnan G. Hydrogel capsules for sustained drug release. J Appl Polymer Sci 1994; 51: 979-88.

[95] Clarke KM, Lantz GC, Salisbury SK, Badylak SF, Hiles MC, Voytik SL. Intestine submucosa and polypropylene mesh for abdominal wall repair in dogs. Curr Drug Ther 2011; 6(4): p. 269.

[96] Jain N, Banik A. Novel interpenetrating polymer network mucoadhesive microspheres of gum ghatti and poly (vinyl alcohol) for the delivery of ranitidine $\mathrm{HCl}$. Asi J Pharm Clin Res 2013; 6(1): 11923.

[97] Barber TA, Ho JE, De RA, Virdi AS, Sumner DR, Healy KE. Periimplant bone formation and implant integration strength of peptide modified $\mathrm{p}(\mathrm{AAM}-\mathrm{co}-\mathrm{EG} / \mathrm{AAC})$ interpenetrating polymer network coated titanium implants. J Biomed Mater Res 2007; 80: 306-20.

[98] Yin L, Ding JY, Fei L, et al. Beneficial properties for insulin absorption using superporous hydrogel containing interpenetrating polymer network as oral delivery vehicles. Int J Pharm 2008; 350: 220-9.

[99] Tigli RS, Gumusderelioglu M. Evaluation of alginate-chitosan semi IPNs as cartilage scaffolds. J Mater Sci Mater Med 2009; 20: 699709.
[100] George J, Onodera J, Miyata T. Biodegradable honeycomb collagen scaffold for dermal tissue engineering. J Biomed Mater Res 2008; 87: 1103-11.

[101] Dandangi PM, Mastiholimath VS, Gadad AP, Iliger SR. Mucoadhesive microsphere of propanol $\mathrm{HCl}$ for nasal delivery. Int J Pharm Sci 2007; 69(3): 402-7.

[102] Kumari K, Kundu PP. Semi-Interpenetrating polymer networks (IPNs) of chitosan and L-alanine for monitoring the release of chlorpheniramine maleate. J Appl Polymer Sci 2007; 103(6): 37517.

[103] Auger FA, Rouabhia M, Goulet F, Berthod F, Moulin V, Germain L. Tissue-engineered human skin substitutes developed from collagen-populated hydrated gels: clinical and fundamental applications. Med Biological Eng Comput 1998; 36: 801-12.

[104] Shanmugasundaram N, Ravichandran P, Reddy PN, Ramamurty N, Pal S, Rao KP. Collagen-chitosan polymeric scaffolds for the in vitro culture of human epidermoid carcinoma cells. Biomaterials 2001; 22: 1943-51.

[105] Kim IY, Yoo MK, Kim BC, Kim SK, Lee HC, Choa CS. Preparation of semi-interpenetrating polymer networks composed of chitosan and poloxamer. Int J Biol Macromol 2006; 38: 51-8.

[106] Takaoka K, Nakahara H, Yoshikawa H, Masuhara K, Tsuda T, Ono $\mathrm{K}$. Ectopic bone induction on and in porous hydroxyapatite combined with collagen and bone morphogenetic protein. Clin Orthop 1998; 234: 250-4.

[107] Risbud MV, Hardikar AA, Bhat SV, Bhonde RR. pH-sensitive freeze-dried chitosan-polyvinyl pyrrolidone hydrogels as controlled release system for antibiotic delivery. J Cont Release 2000; 68: 23-30.

[108] Liu L, Zhang L, Ren B, Wang F, Zhang Q. Preparation and characterization of collagen-hydroxyapatite composite used for bone tissue engineering scaffold. Artific Cells Blood Subst Immobiliz Biotechnol 2003; 31: 435-48.

[109] Moullier P, Marechal V, Danos O, Heard JM. Continuous systemic secretion of lysosomal enzyme by genetically-modified mouse skin fibroblasts. Transplantation 1993; 56: 427-32.

[110] Rao KSPV, Naidu BVK, Subha MCS, Sairam M, Aminabhavi TM. Novel chitosan-based $\mathrm{pH}$-sensitive interpenetrating network microgels for the controlled release of cefadroxil. Carbohydr Polymer 2006; 66: 333-44.

[111] Myung D, Farooqui N, Zheng L, et al. Bio-active interpenetrating polymer network hydrogels that support corneal epithelial wound healing. J Biomed Mater Res 2009; 90(1): 70-81.

[112] Bhatt N, Bhatt G, Kothiyal P. pH-responsive semi-interpenetrating polymeric hydrogels microspheres of chitosan and poly vinyl alcohol for in-vitro controlled release of clarithromycin. Int J Pharmacother 2014; 4(2): 68-73

[113] Mallikarjuna B, Rao KM, Sudhakar P, Rao KC, Subha MCS. Chitosan based biodegradable hydrogel microspheres for controlled release of an Anti-HIV drug. J Adv Chem Sci 2013; 1(3): 144-51

[114] Steffensen SL, Vestergaard MH, Moller EH, et al. Soft hydrogels interpenetrating silicone: a polymer network for drug-releasing medical devices. J Biomed Mater Res Part B: Appl Biomater 2015; 00B(00): 1-9.

(c) Qadri et al.; Licensee Bentham Open.

This is an open access article licensed under the terms of the (https://creativecommons.org/licenses/by/4.0/legalcode), which permits unrestricted, noncommercial use, distribution and reproduction in any medium, provided the work is properly cited. 